\title{
MÉTODOS DE PREPARAÇÃO DE NANOPARTÍCULAS METÁLICAS SUPORTADAS EM CARBONO DE ALTA ÁREA SUPERFICIAL, COMO ELETROCATALISADORES EM CÉLULAS A COMBUSTÍVEL COM MEMBRANA TROCADORA DE PRÓTONS
}

\author{
Estevam V. Spinacé*, Almir Oliveira Neto, Egberto G. Franco e Marcelo Linardi \\ Centro de Ciência e Tecnologia de Materiais, Instituto de Pesquisas Energéticas e Nucleares, Av. Prof. Lineu Prestes, 2242, \\ 05508-900 São Paulo - SP \\ Ernesto R. Gonzalez \\ Instituto de Química de São Carlos, Universidade de São Paulo, CP 780, 13560-970 São Carlos - SP
}

Recebido em 17/6/03; aceito em 24/11/03; publicado na web em 27/05/04

\begin{abstract}
METHODS OF PREPARATION OF METAL NANOPARTICLES SUPPORTED ON HIGH SURFACE AREA CARBON AS ELECTROCATALYSTS IN PROTON EXCHANGE MEMBRANE FUEL CELLS. Fuel cells are attracting much interest as efficient and clean energy conversion devices. The main components of low temperature fuel cells are the electrocatalysts used to promote the anodic and cathodic reactions, which are based on platinum and platinum alloys. These electrocatalysts are normally prepared in the form of metal nanoparticles supported on a conductive material, usually high surface area carbon, to improve catalyst utilization and reduce cost. This work presents and comments some methods used presently to produce these electrocatalysts. The performances of the produced electrocatalysts are compared to that of state-of-the-art commercial E-TEK electrocatalysts.
\end{abstract}

Keywords: electrocatalysts; fuel cells; electro-oxidation.

\section{INTRODUÇÃO}

Nos dias de hoje, as principais fontes de energia para diversas aplicações são os combustíveis fósseis, utilizados em máquinas térmicas, em motores de combustão interna (veiculares e estacionários), em caldeiras industriais, etc. Estes combustíveis, além de não renováveis, produzem quantidades consideráveis de poluentes como o $\mathrm{CO}_{2}, \mathrm{CO}, \mathrm{NO}_{\mathrm{x}}, \mathrm{SO}_{\mathrm{x}}$, hidrocarbonetos e particulados, extremamente nocivos para a saúde e responsáveis por fenômenos atmosféricos indesejáveis como, por exemplo, o efeito estufa e a chuva ácida ${ }^{1}$.

Uma conversão mais eficiente de energia, partindo de fontes renováveis ou não, aparece como uma necessidade cada vez mais crescente no mundo moderno. Existe grande interesse em se pesquisar sistemas de geração de energia mais eficientes, menos poluentes e menos nocivos à saúde do homem, tendo em vista o controle da poluição ambiental. Nos grandes centros urbanos, onde circulam diariamente grande número de veículos movidos a combustíveis fósseis, o problema de poluição atmosférica está atingindo níveis alarmantes ${ }^{2}$.

As células a combustível têm-se mostrado uma alternativa interessante e promissora na solução dos problemas da geração de energia elétrica limpa e com alta eficiência, e apresentam grandes possibilidades para a conversão de energia no futuro. As células atuais mais eficientes operam oxidando hidrogênio no ânodo e reduzindo oxigênio no cátodo. Já se encontram no mercado células a combustível com eficiência elétrica de $45 \%$ e eficiência total (elétrica + térmica) superior a $80 \%$, aproveitando-se, também, o calor gerado pela própria célula (co-geração). Um problema ainda encontrado pela tecnologia de células a combustível é o seu elevado custo de entrada no mercado ${ }^{3-6}$.

Diversos tipos de células estão sendo pesquisados e desenvolvidos, sendo uma das que atrai maior interesse a célula a combustível de membrana trocadora de prótons "Proton Exchange Membrane Fuel Cell - PEMFC". Estas células apresentam uma elevada densidade de

*e-mail: espinace@ipen.br potência e podem começar a operar à temperatura ambiente. A platina é o principal metal utilizado nos eletrocatalisadores, podendo ser usado tanto para a oxidação anódica quanto para a redução catódica, aumentando consideravelmente a cinética das reações eletródicas e possibilitando o desenvolvimento tecnológico das células a combustível. Por outro lado, o alto custo da platina e o comprometimento das reservas no caso de um uso generalizado limitam sua utilização. Com o advento dos eletrodos de difusão de gás esta limitação foi significativamente reduzida, pois a platina na forma de nanopartículas é dispersa em carbono de alta área superficial, sendo necessário apenas pequenas quantidades de metal (frações de $\mathrm{mg} / \mathrm{cm}^{2}$ ) para catalisar as reações ${ }^{3-6}$. O eletrolito utilizado nas PEMFC é uma membrana trocadora de prótons, portanto na forma ácida, sendo geralmente utilizada a membrana de Nafion ${ }^{\circledR}$ (Du Pont). As reações que ocorrem nos eletrodos de difusão de gás para o sistema $\mathrm{H}_{2} / \mathrm{O}_{2}$ são:

Anódica: $\mathrm{H}_{2} \rightarrow 2 \mathrm{H}^{+}+2 \mathrm{e}^{-}$

Catódica: $1 / 2 \mathrm{O}_{2}+2 \mathrm{e}^{-}+2 \mathrm{H}^{+} \rightarrow \mathrm{H}_{2} \mathrm{O}$

O oxigênio pode ser obtido diretamente do ar atmosférico, enquanto a forma mais barata de obter o hidrogênio é através do processo de reforma catalítica de um combustível primário rico em hidrogênio (renovável ou não). Neste processo uma certa quantidade de monóxido de carbono é formada como sub-produto da reação. A presença de monóxido de carbono (> 10 ppm) no hidrogênio leva a um envenenamento da platina, pois se adsorve fortemente nos sítios ativos para a reação (adsorção química). Desse modo, alguns ppm de CO na alimentação de hidrogênio levam a uma queda no desempenho da célula em mais de $80 \%$. Uma alternativa para contornar este problema é adicionar um segundo metal à platina (co-catalisador), por exemplo o rutênio, o qual leva à formação de espécies oxigenadas em potenciais inferiores a $0,25 \mathrm{~V}$, facilitando a oxidação do $\mathrm{CO}$ a $\mathrm{CO}_{2}$. Quando se utiliza somente platina, as espécies oxigenadas são formadas em potenciais acima de $0,8 \mathrm{~V}$, diminuindo a eficiência do processo ${ }^{3-6}$. 
O hidrogênio apresenta também alguns inconvenientes operacionais e de infra-estrutura. A compressão, o armazenamento e a distribuição do hidrogênio requerem tecnologias relativamente sofisticadas e de custo elevado, o que dificulta o uso deste combustível, particularmente em certas aplicações que seriam de grande impacto, como a utilização em veículos e em equipamentos portáteis. Devido a esta constatação, têm surgido esforços significativos para desenvolver células a combustível que possam operar diretamente com combustíveis líquidos ${ }^{3-6}$. Neste sentido, o combustível que atualmente apresenta resultados encorajadores para ser utilizado diretamente é o metanol e esforços estão sendo feitos para viabilizar o uso direto do etanol ${ }^{7}$, sendo este último de grande interesse para o Brasil. O metanol tem sido utilizado diretamente como combustível em células de membrana trocadora de prótons "Direct Methanol Fuel Cell - DMFC" ". Esta célula é alimentada com metanol na forma de vapor ou líquido e opera em baixas temperaturas $\left(<100{ }^{\circ} \mathrm{C}\right)$. Idealmente as reações que ocorrem em células a metanol direto são:

ânodo: $\mathrm{CH}_{3} \mathrm{OH}+\mathrm{H}_{2} \mathrm{O} \rightarrow \mathrm{CO}_{2}+\mathrm{H}^{+}+6 \mathrm{e}^{-}$

cátodo: $3 / 2 \mathrm{O}_{2}+6 \mathrm{e}^{-}+6 \mathrm{H}^{+} \rightarrow 3 \mathrm{H}_{2} \mathrm{O}$

A reação de eletro-oxidação completa do metanol produz 6 elétrons e o potencial padrão da $\operatorname{DMFC}(1,20 \mathrm{~V})$ não é muito diferente do potencial da PEMFC (1,23 V). Entretanto, a reação é bastante lenta, como resultado da formação de intermediários fortemente adsorvidos como o monóxido de carbono $\left(\mathrm{CO}_{\text {ads }}\right)$, resultando em potenciais operacionais bem menores. A oxidação desses intermediários a $\mathrm{CO}_{2}$ requer a participação de espécies que contem oxigênio $\left(\mathrm{OH}, \mathrm{H}_{2} \mathrm{O}\right)$, que devem ser adsorvidas também nos sítios ativos do catalisador. A platina sozinha não é suficientemente ativa para a oxidação do $\mathrm{CO}_{\text {ads }}$ a $\mathrm{CO}_{2}$ porque, como mencionado acima, essas espécies se formam em potenciais relativamente elevados. Por isso, na presença de $\mathrm{CO}$ é necessário utilizar materiais alternativos como ligas de platina-rutênio. Nestes catalisadores, o metal ligado à platina forma óxidos superficiais em potenciais mais baixos facilitando a oxidação dos intermediários da reação, através do chamado mecanismo bifuncional ${ }^{8}$.

O método convencional de preparação de catalisadores metálicos suportados é a impregnação dos sais metálicos no suporte e posterior redução, freqüentemente em fluxo de hidrogênio a alta temperatura. No entanto, esta metodologia não possibilita um controle satisfatório do tamanho, da composição e da dispersão das partículas metálicas formadas ${ }^{9}$. Neste trabalho são descritos alguns métodos de preparação de eletrocatalisadores que possibilitam maior controle desses fatores, o que é de extrema importância, pois a atividade catalítica é fortemente influenciada por eles. Estes métodos estão sendo desenvolvidos e/ ou estudados pelos grupos de células a combustível do IQSC/USP e do IPEN/CNEN-SP e permitem obter materiais mais ativos para as reações que ocorrem nas PEMFC, tanto para a oxidação direta de metanol e etanol, como de misturas gasosas, por exemplo hidrogênio contendo $\mathrm{CO}$, provenientes da reforma de combustíveis primários. Portanto, o estudo e o conhecimento destes métodos, bem como o desenvolvimento de novos métodos de preparação de catalisadores nano-estruturados de baixo custo, visando um melhor desempenho para as células a combustível são cruciais para o avanço desta tecnologia e para reduzir o custo de entrada no mercado. Na literatura, o desempenho dos eletrocatalisadores obtidos por diferentes metodologias é usualmente comparado aos eletrocatalisadores comerciais E-TEK, os quais são considerados como referência em termos de desempenho ${ }^{10}$.

\section{MÉTODO DO ÁCIDO FÓRMICO}

O método do ácido fórmico foi desenvolvido no Instituto de
Química de São Carlos-USP (Grupo de Eletroquímica) com a finalidade de preparar catalisadores de platina dispersa suportados em carbono (Pt/C) para estudos em células a combustível do tipo $\mathrm{PEMFC}^{11}$. O método do ácido fórmico consiste na preparação de eletrocatalisadores via redução química, visando alta atividade catalítica e quantidade reduzida de metal nobre. Foi demonstrado que os eletrocatalisadores $\mathrm{Pt} / \mathrm{C}$ preparados pelo método do ácido fórmico apresentaram alta atividade catalítica, tanto para a reação de oxidação de hidrogênio no ânodo, quanto para a reação de redução de oxigênio no cátodo. Posteriormente, este método foi adaptado para preparação de ligas de platina com certos metais de transição visando aplicações na eletro-oxidação de metanol e de etanol. Nestes casos, o método mostrou-se também eficiente para a preparação de catalisadores para as reações estudadas ${ }^{11}$. A metodologia de preparação de eletrocatalisadores pelo método do ácido fórmico é bastante simples: inicialmente o pó de carbono de alta área superficial (Vulcan XC-72, Cabot, $240 \mathrm{~m}^{2} \mathrm{~g}^{-1}$ ) é adicionado a uma solução de ácido fórmico e a mistura é aquecida a $80{ }^{\circ} \mathrm{C}$. Uma solução contendo os sais de platina e do co-catalisador é adicionada em etapas. Para o controle do andamento da redução, utiliza-se o iodeto de potássio como reagente externo, com a finalidade de indicar a presença de platina em solução (vermelho intenso). Após a redução total da platina não se observa mais o tom avermelhado e novas adições da solução contendo os íons metálicos podem ser realizadas. Após a redução total da platina, o catalisador é filtrado, seco e triturado ${ }^{11}$.

Oliveira Neto e colaboradores ${ }^{11}$ prepararam eletrocatalisadores $\mathrm{Pt}: \mathrm{Ru}$ pelo método do ácido fórmico a partir de composições atômicas Pt:Ru de 90:10, 80:20, 70:30 e 60:40. Os eletrocatalisadores obtidos foram caracterizados pelas técnicas de análise de espectroscopia de dispersão de energia de raios-X (EDX), difração de raios-X (XRD) e microscopia eletrônica de transmissão (TEM). A caracterização eletroquímica foi realizada por voltametria cíclica. Os resultados de difração de raios-X mostraram que as partículas metálicas encontram-se na forma de ligas e apresentam a estrutura cúbica de face centrada da platina, que predomina nas ligas. As análises por EDX mostraram que as composições atômicas das ligas $\mathrm{Pt}: \mathrm{Ru}$ obtidas foram semelhantes às composições de partida. As micrografias obtidas por TEM apresentaram uma faixa estreita de distribuição de tamanho de partículas variando de 1,6 a $6,4 \mathrm{~nm}$, sendo que cerca de $50 \%$ das partículas encontram-se na faixa de $3 \mathrm{~nm}$. Os tamanhos de partículas são similares aos do eletrocatalisador comercial Pt:Ru 50:50 da E-TEK utilizado para comparação.

Na Figura 1 são mostrados os resultados obtidos por voltametria cíclica para a eletro-oxidação de metanol utilizando os eletrocatalisadores Pt:Ru de diferentes composições, preparados pelo método do ácido fórmico, e o eletrocatalisador Pt:Ru 50:50 E-TEK (20\% em massa de $\mathrm{Pt}+\mathrm{Ru})^{11}$.

As ligas de platina com 10, 20 e 30\% de rutênio apresentaram melhor atividade catalítica em relação ao catalisador comercial da E-TEK, em toda a faixa de potencial estudada. Considerando a faixa de potencial para aplicações tecnológicas $(0,3$ a $0,6 \mathrm{~V})$ podemos dizer que as ligas com 10 e $20 \%$ de rutênio apresentaram-se mais ativas para a eletro-oxidação de metanol. O catalisador com $40 \%$ de rutênio apresentou desempenho inferior aos demais catalisadores, no entanto, sua atividade catalítica é superior ao catalisador comercial da E-TEK até potenciais de 0,45 V. Acima destes potenciais o catalisador da E-TEK apresentou melhor desempenho. Os resultados da Figura 1 estão em acordo com os obtidos por Gasteiger e colaboradores $^{12}$, onde ligas com teores em torno de $10 \%$ de rutênio, preparadas pelo método de deposição eletroquímica, foram as mais ativas para a eletro-oxidação de metanol. Isto ocorre porque há um número máximo de átomos de platina necessários para adsorção dissociativa de metanol enquanto o rutênio fornece espécies $\mathrm{OH}$ em 


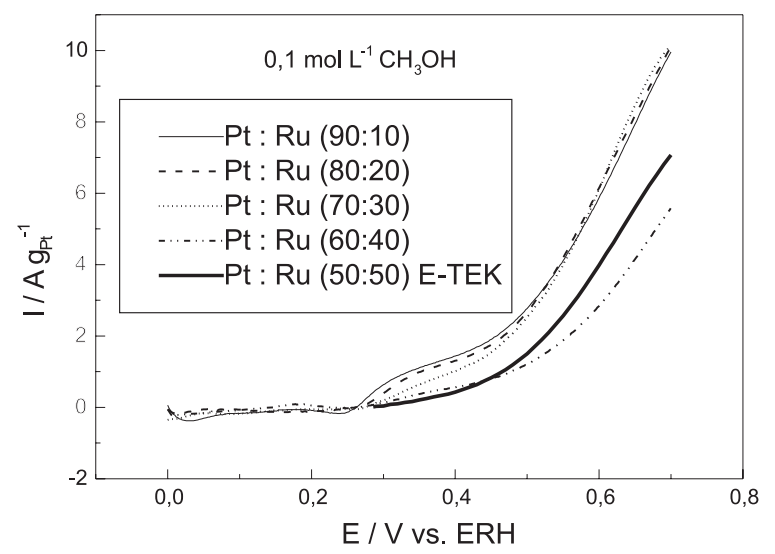

Figura 1. Comparação das correntes dos catalisadores de PtRu preparados pelo método do ácido fórmico com relação ao catalisador comercial E-TEK a $10 \mathrm{mV} \mathrm{s}^{-1}$, considerando-se apenas a varredura anódica em $0,5 \mathrm{~mol} \mathrm{~L}^{-1}$ de $\mathrm{H}_{2} \mathrm{SO}_{4}$ na presença de metanol 0,1 $\mathrm{mol} \mathrm{L}^{-1}$. As correntes foram normalizadas pela quantidade de platina e corrigidas com relação à corrente no eletrólito suporte ${ }^{l l}$

sítios adjacentes. Estas conclusões são válidas à temperatura ambiente, quando o metanol não se adsorve sobre o rutênio.

Na Figura 2 são mostrados os resultados obtidos por voltametria cíclica para a eletro-oxidação de etanol na presença dos eletrocatalisadores Pt e Pt:Ru preparados pelo método do ácido fórmico.

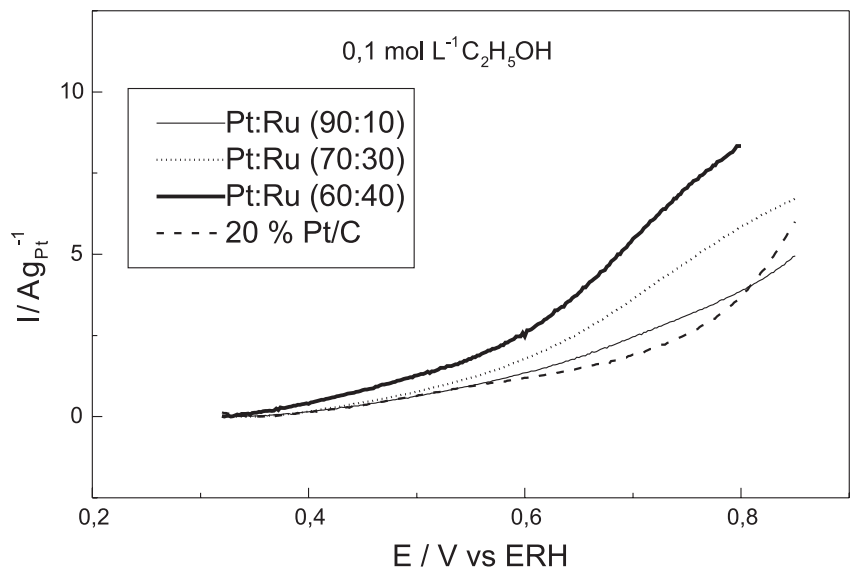

Figura 2. Comparação dos eletrocatalisadores Pt e PtRu preparados pelo método do ácido fórmico na eletro-oxidação de etanol $0,1 \mathrm{~mol} \mathrm{~L}^{-1}$ em solução de $\mathrm{H}_{2} \mathrm{SO}_{4} 0,5 \mathrm{~mol} \mathrm{~L}^{-1}$ a $10 \mathrm{mV} \mathrm{s}^{-1}$. As correntes foram normalizadas pela quantidade de platina e corrigidas com relação à corrente no eletrólito suporte $^{11}$

Até potenciais de $0,8 \mathrm{~V}$ o catalisador Pt:Ru (60:40) apresentou os maiores valores de corrente, seguido pelo 70:30 o 90:10 e por último, pela platina dispersa. Acima de $0,8 \mathrm{~V}$ a platina dispersa apresentou os maiores valores de corrente em relação ao Pt:Ru (90:10), no entanto, esta região de potencial não tem interesse prático. Resultados semelhantes foram obtidos por Fujiwara e colaboradores ${ }^{13}$ mostrando que catalisadores com altos teores de rutênio apresentaram maiores atividades para a oxidação de etanol. Estes resultados podem ser explicados pelos mecanismos diferentes que operam na oxidação de etanol e de metanol. A oxidação de etanol é mais complexa por requerer a transferência de um número maior de elétrons, formar um número maior de intermediários adsorvidos e apresentar o problema adicional da ruptura da ligação C-C.

\section{MÉTODO DE BÖNNEMANN}

O método de Bönnemann, também conhecido como método coloidal, pode ser utilizado para a obtenção de catalisadores mistos ou sistemas de catalisadores, ternários e quaternários, sobre carvão ativo e carvão ativo grafitizado. Esta metodologia pode ser aplicada com sucesso para a obtenção de eletrocatalisadores à base de platina e ligas contendo metais (e/ou óxidos de metais), em particular, Sn, V, W e Mo e demais elementos de transição, como $\mathrm{Cu}, \mathrm{Fe}, \mathrm{Co}$ e $\mathrm{Ni}^{14-17}$.

Este método, numa versão modificada ${ }^{14}$, consiste na preparação de um sistema coloidal em atmosfera inerte, utilizando-se solventes e sais desidratados, o que encarece o método.Os sais anidros dos metais são dissolvidos nas proporções desejadas em tetraidrofurano (THF) anidro $\left(\left[\mathrm{H}_{2} \mathrm{O}\right]<0,005 \%\right)$ junto com uma quantidade apropriada de brometo de tetraoctilamônio ( $\left.\mathrm{N}(\mathrm{oct}){ }_{4} \mathrm{Br}\right)$. $\mathrm{O}$ agente redutor é preparado com a mistura de soluções de $\mathrm{N}($ oct $){ }_{4} \mathrm{Br}$ em THF e uma solução de trietilidroborato de potássio $\left(\mathrm{KHB}(\mathrm{et})_{3}\right)$ em THF. Formase então uma solução de trietilidroborato de tetraoctilamônio $\left(\mathrm{N}(\mathrm{oct})_{4} \mathrm{HB}(\mathrm{et})_{3}\right)$, um forte redutor, como indicado pela Equação 5:

$\mathrm{N}(\text { oct })_{4} \mathrm{Br}+\mathrm{KHB}(\mathrm{et})_{3} \rightarrow \mathrm{N}(\text { oct })_{4} \mathrm{HB}(\mathrm{et})_{3}+\mathrm{KBr}$

Para a redução dos íons metálicos utiliza-se uma vez e meia a quantidade estequiométrica da solução de $\mathrm{N}(\text { oct })_{4} \mathrm{HB}(\mathrm{et})_{3}$, que é adicionada à solução dos sais dos metais a $40{ }^{\circ} \mathrm{C}$ sob agitação. A redução pode ser observada pelo escurecimento e geração de hidrogênio como mostrado na Equação 6:

$\mathrm{MeX}_{\mathrm{n}}+\mathrm{N}(\text { oct })_{4} \mathrm{HB}(\mathrm{et})_{3} \rightarrow \mathrm{Me}^{*}\left[\mathrm{~N}(\mathrm{oct})_{4}\right]^{+}+\mathrm{nB}(\mathrm{et})_{3}+\mathrm{n} / 2 \mathrm{H}_{2}+\mathrm{nX}^{-}$

A dispersão coloidal é, então, agitada à temperatura ambiente e o colóide é formado pela adsorção do íon $\left[\mathrm{N}(\mathrm{oct})_{4}\right]^{+}$na superfície do metal/liga dos metais, o que garante a dimensão nanométrica das partículas e sua grande solubilidade em solventes orgânicos. Todas as etapas até a formação do colóide são realizadas em atmosfera controlada. Após a agitação, a dispersão coloidal é vagarosamente adicionada à suspensão de pó de carbono (suporte) em THF ${ }^{14}$.

Resíduos de íons $\left[\mathrm{N}(\mathrm{oct})_{4}\right]^{+}$ainda permanecem ligados às nanopartículas após a preparação do catalisador suportado, prejudicando o desempenho eletroquímico. Segundo Schmidt e colaboradores ${ }^{18}$ pode-se eliminar os íons $\left[\mathrm{N}(\mathrm{oct})_{4}\right]^{+}$por oxidação, submetendo o catalisador à passagem de um fluxo de 10\% oxigênio/90\% nitrogênio, seguido de um fluxo de hidrogênio a $300{ }^{\circ} \mathrm{C}$.

Franco e colaboradores ${ }^{19}$ prepararam no IPEN/CNEN-SP eletrocatalisadores ternários Pt:Ru:Mo com razões atômicas 1:1:1 e 1:1:0,5 pelo método de Bönnemann. As análises por microscopia eletrônica de transmissão (Figura 3) mostraram que, para ambos os eletrocatalisadores, as nanopartículas apresentavam-se bem distribuídas e possuíam tamanhos de cerca de $2 \mathrm{~nm}$.

As análises das nanopartículas pela técnica de nano-EDX mostraram variações nas composições nominais. Para o eletrocatalisador com razão atômica de 1:1:1, o valor obtido foi de 1,0:0,7:1,0 e para o de razão nominal 1:1:0,5, foi de 1:0,8:0,6. As análises por espectroscopia de fotoelétrons excitados por raios-X (XPS) foram usadas para investigar as espécies químicas presentes na superfície dos eletrocatalisadores. Foram detectadas espécies como platina metálica, $\mathrm{PtO}_{2}, \mathrm{RuO}_{2}, \mathrm{RuO}_{2} \cdot \mathrm{xH}_{2} \mathrm{O}$ e espécies oxidadas de molibdênio, que não puderam ser atribuídas a compostos específicos.

Experimentos eletroquímicos utilizando a técnica de voltametria cíclica mostraram que a superfície dos eletrocatalisadores, não submetidos ao tratamento térmico após a síntese, poderia estar recoberta por espécies provenientes do agente redutor. Para confirmar estes 


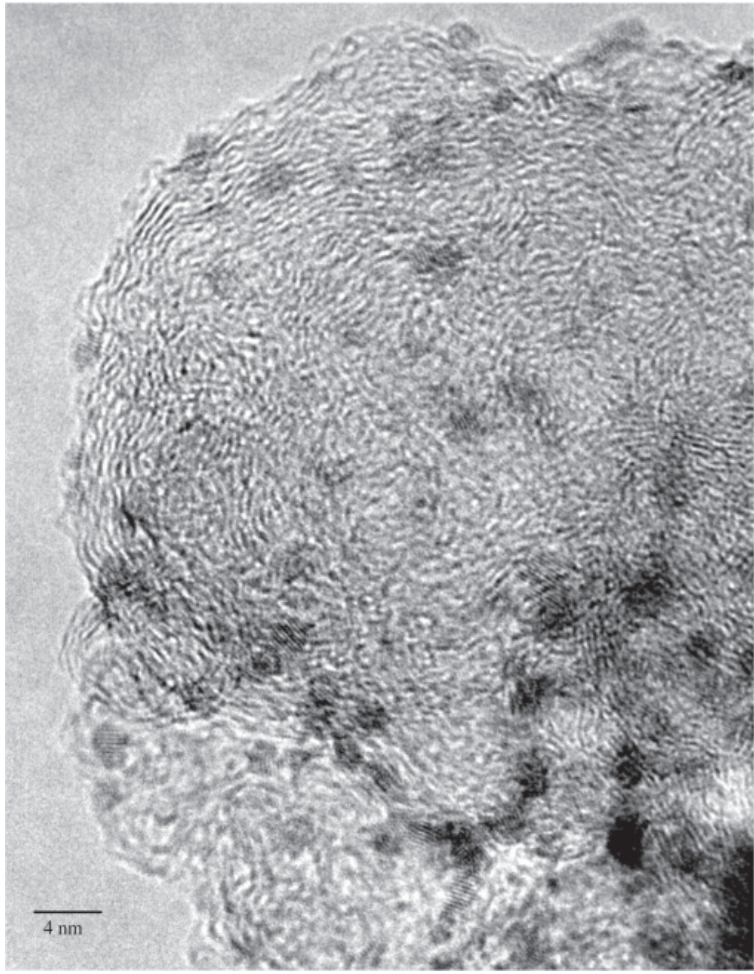

Figura 3. TEM do eletrocatalisador PtRuMo $(1: 1: 1)^{19}$

resultados foram realizados experimentos utilizando a técnica de espectroscopia na região do infravermelho. Os espectros de infravermelho dos eletrocatalisadores sem tratamento térmico revelaram a presença de bandas na região entre 2900 e $2800 \mathrm{~cm}^{-1}$, correspondente ao estiramento $\mathrm{CH}_{3}$ e $\mathrm{CH}_{2}$ assimétrico e simétrico da espécie tetraoctilamônio ${ }^{20}$

Os eletrocatalisadores Pt:Ru:Mo foram avaliados na eletro-oxidação de metanol, utilizando a técnica de eletrodo de camada fina porosa $^{21}$. Na Figura 4 ilustra-se uma comparação dos valores de correntes por grama de Pt obtidos para os diferentes eletrocatalisadores preparados pelo método de Bönnemann em solução $1 \mathrm{~mol} \mathrm{~L}^{-1}$ de metanol, considerando-se apenas a varredura anódica.

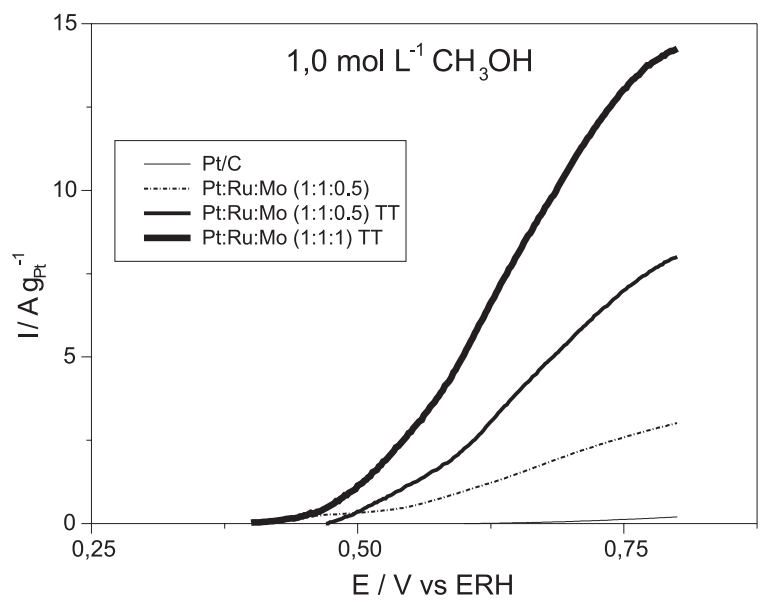

Figura 4. Eletro-oxidação de metanol para os eletrocatalisadores de Pt, Pt:Ru:Mo (1:1:0,5), Pt:Ru:Mo (1:1:0,5)TT, Pt:Ru:Mo (1:1:1)TT preparados pelo método de Bönnemann, considerando-se apenas a varredura anódica. As correntes foram normalizadas pela quantidade de platina e corrigidas com relação à corrente no eletrólito suporte ${ }^{19}$
Na Figura 4 nota-se que todos os eletrocatalisadores Pt:Ru:Mo apresentaram um melhor desempenho em relação ao de Pt. Este fato ilustra o efeito benéfico da adição do segundo e terceiro metais à platina por este método, resultando em menor envenenamento do catalisador $^{20,22,23}$. Em $0,5 \mathrm{~V}$, potencial de interesse em aplicações tecnológicas, o catalisador de Pt:Ru:Mo (1:1:1) com tratamento térmico (TT) apresentou melhor desempenho com relação aos demais catalisadores para a oxidação de metanol. Estes resultados mostram também a necessidade de tratamentos térmicos para os eletrocatalisadores preparados pelo método de Bönnemann, a fim de eliminar as espécies orgânicas provenientes do agente redutor, que podem recobrir os sítios ativos do eletrocatalisador ${ }^{24}$.

O eletrocatalisador Pt:Ru:Mo (1:1:0,5) tratado termicamente foi testado em uma célula a combustível unitária operando com hidrogênio e os resultados foram comparados aos do eletrocatalisador comercial E-TEK. As curvas de polarização (Figura 5) mostraram que o eletrocatalisador preparado pelo método de Bönnemann é muito promissor para aplicação em células tipo $\mathrm{PEMFC}^{19}$.

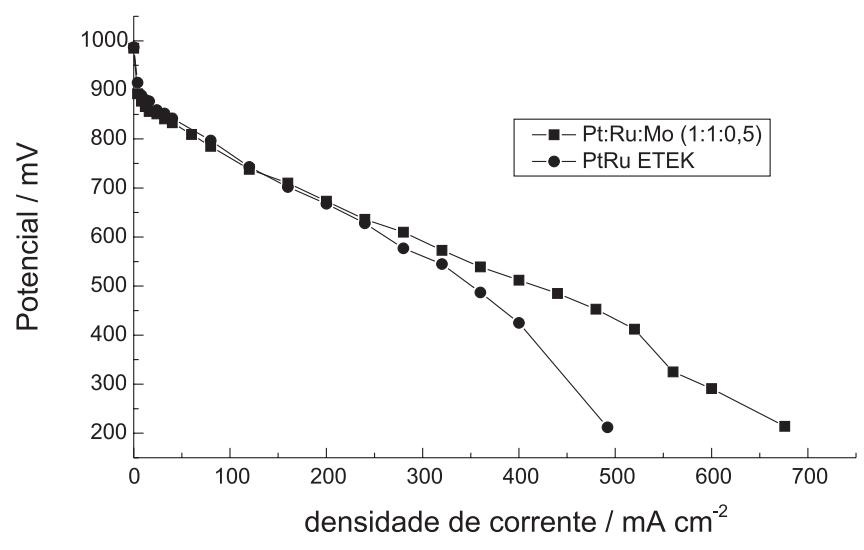

Figura 5. Curva de polarização obtida em uma célula a combustível unitária para os eletrocatalisadores Pt:Ru:Mo (1:1:0,5) e PtRu (1:1) E-TEKoperando com hidrogênio puro. (Temperatura de operação da célula: $75^{\circ} \mathrm{C}$, fluxo de

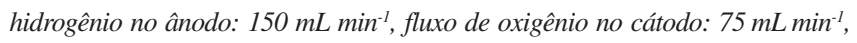
temperatura de umidificação do gás no ânodo: $85^{\circ} \mathrm{C}$, catalisador no ânodo: 0,4 mg de metal por $\mathrm{cm}^{-2}$, catalisador no cátodo: 0,4 mg Pt por $\mathrm{cm}^{2}$, área do MEA: $\left.25 \mathrm{~cm}^{2}\right)^{19}$

\section{MÉTODO DA DEPOSIÇÃO ESPONTÂNEA}

Um grande esforço vem sendo realizado nos últimos anos para desenvolver um sistema de eletrocatalisadores que apresente alta atividade e uma quantidade reduzida de metal nobre. Recentemente, Adzic e colaboradores ${ }^{25-27}$ relataram um novo método de preparação do eletrocatalisador Pt:Ru, o qual reduz consideravelmente a quantidade de platina empregada. Segundo os autores, somente um quarto de uma monocamada de platina sobre nanopartículas de rutênio resulta em um eletrocatalisador com maior atividade e tolerância ao envenenamento da Pt pelo monóxido de carbono, na oxidação de misturas $\mathrm{H}_{2} / \mathrm{CO}$ (100 ppm de $\mathrm{CO}$ ), em comparação com eletrocatalisadores comerciais contendo ligas $\mathrm{Pt}: \mathrm{Ru}$. O método de preparação deste eletrocatalisador envolve a deposição espontânea de platina sobre nanopartículas de rutênio suportadas em carbono, sem a aplicação de um potencial externo. Inicialmente, as nanopartículas de rutênio suportadas no carbono Vulcan XC-72 são tratadas em atmosfera de hidrogênio a $300{ }^{\circ} \mathrm{C}$ por $2 \mathrm{~h}$. Posteriormente, são esfriadas à temperatura ambiente e imersas em uma solução contendo íons $\left[\mathrm{PtCl}_{6}\right]^{2-}$. O procedimento completo é realizado em atmosfera de hidrogênio e/ou argônio e a quantidade de platina disponível para a 
deposição espontânea é controlada pela concentração e volume da solução de imersão. Dessa forma ocorre a formação de depósitos de platina desde frações de monocamadas até multicamadas, sem a aplicação de um campo externo.

Em relação ao mecanismo da deposição espontânea de um metal nobre sobre outro metal ainda não existe consenso. A deposição pode ser atribuída a uma reação química com o hidrogênio adsorvido ou a um mecanismo envolvendo a formação de espécies $\mathrm{M}-\mathrm{OH}$ na superfície (Equações 7 e 8).

$$
\begin{aligned}
& \mathrm{Ru}^{0}+\mathrm{x}\left(\mathrm{H}_{2} \mathrm{O}\right) \rightarrow \mathrm{RuO}_{x} \mathrm{H}_{y}+(2 \mathrm{x}-\mathrm{y}) \mathrm{H}^{+}+(2 \mathrm{x}-\mathrm{y}) \mathrm{e}^{-} \\
& {\left[\mathrm{PtCl}_{6}\right]^{2-}+4 \mathrm{e}^{-} \rightarrow \mathrm{Pt}^{0}+6 \mathrm{Cl}^{-}}
\end{aligned}
$$

A atividade catalítica dos eletrocatalisadores Pt:Ru, obtidos pela deposição espontânea, foi determinada a partir de experimentos utilizando o eletrodo rotativo de camada fina porosa. $\mathrm{Na}$ oxidação de $\mathrm{H}_{2}$ em $\mathrm{H}_{2} \mathrm{SO}_{4} 0,5 \mathrm{~mol} \mathrm{~L}^{-1}$ a $25^{\circ} \mathrm{C}$, a atividade foi cerca de três vezes maior, considerando-se a densidade de corrente por massa de platina, quando comparada ao eletrocatalisador comercial E-TEK (liga $\mathrm{Pt}: \mathrm{Ru})^{25}$. Quando a oxidação de $\mathrm{H}_{2}$ é realizada na presença de $100 \mathrm{ppm}$ de CO os eletrocatalisadores obtidos por deposição espontânea apresentaram uma perda de atividade de $15 \%$ após $1 \mathrm{~h}$, enquanto que a perda no eletrocatalisador da E-TEK foi maior que 50\%. Esta significante tolerância ao $\mathrm{CO}$, mostrada à temperatura ambiente, pode ser intensificada na operação da célula a combustível a aproximadamente $80^{\circ} \mathrm{C}$. A alta tolerância ao $\mathrm{CO}$ foi atribuída à combinação de efeitos eletrônicos e de um mecanismo bifuncional ${ }^{25}$. Como conseqüência das propriedades eletrônicas modificadas da monocamada de platina sobre o rutênio, espera-se que a ligação do $\mathrm{CO}$ com a platina e o rutênio seja mais fraca quando comparada à dos metais em fases puras. $\mathrm{O}$ mecanismo bifuncional é freqüentemente citado na literatura para materiais $\mathrm{Pt}: \mathrm{Ru}$, devido à formação de espécies $\mathrm{RuOH}$ a baixos potenciais, facilitando a oxidação do $\mathrm{CO}^{25}$.

Wieckowski e colaboradores ${ }^{28,29}$ prepararam eletrocatalisadores através da deposição espontânea de rutênio sobre nanopartículas de platina e testaram a atividade na oxidação de metanol. A deposição espontânea envolveu a imersão da platina em uma solução de cloreto de rutênio. Os eletrocatalisadores obtidos foram duas vezes mais ativos, em termos de densidade de corrente por área superficial de platina, que os catalisadores comerciais.

Os estudos preliminares desenvolvidos no IPEN/CNEN-SP utilizando o método da deposição espontânea mostraram-se bastante promissores $^{30}$. Os resultados de voltametria cíclica frente à eletrooxidação de metanol, considerando-se apenas a varredura anódica, para materiais Pt:Ru são apresentados na Figura 6.

$\mathrm{Na}$ Figura 6 pode-se observar que em torno de $0,5 \mathrm{~V}$, potencial de interesse em aplicações tecnológicas de células a combustível, o eletrocatalisador $\mathrm{PtRu} / \mathrm{C}$, preparado com $15 \mathrm{~min}$ de tempo de deposição e $10 \%$ em massa de Ru, apresentou os maiores valores de intensidade de corrente, em relação aos demais eletrocatalisadores, indicando ser este um sistema promissor para futuros testes em células a combustível de metanol direto (DMFC). Os sistemas PtRu/C apresentaram melhor desempenho em relação ao $\mathrm{Pt} / \mathrm{C}$ nos potenciais de interesse. Estes resultados ilustram o efeito benéfico da adição de co-catalisadores à platina.

\section{PREPARAÇÃO DE ELETROCATALISADORES A PARTIR DA DECOMPOSIÇÃO DE PRECURSORES MOLECULARES}

O método convencional de preparação de catalisadores bimetálicos suportados (impregnação dos sais metálicos no suporte e posterior redução) não possibilita um controle satisfatório do tamanho, da dis-

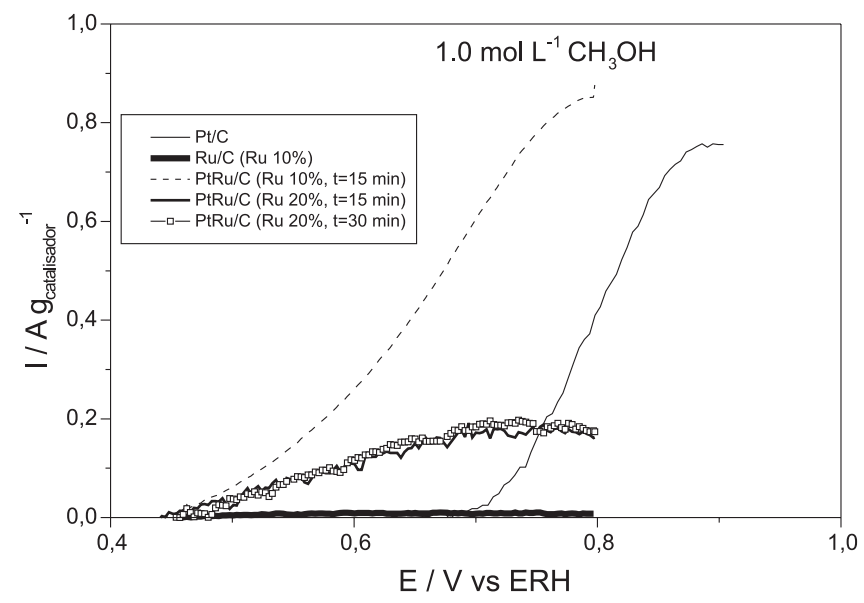

Figura 6. Eletro-oxidação de metanol para os diferentes eletrocatalisadores, considerando-se a varredura anódica. As correntes foram normalizadas pela quantidade de eletrocatalisador e corrigidas com relação à corrente no eletrólito suporte ${ }^{30}$

persão e, principalmente, da composição das partículas metálicas resultantes. Uma alternativa é o uso de clusters ou complexos bimetálicos como precursores. Dessa maneira, espera-se que a composição das nanopartículas que resultam da ativação dessas moléculas sejam semelhantes à de seus precursores, pois suas agregações e crescimento devem ser diferentes daqueles feitos a partir da mistura de sais metálicos. Nuzzo e Shapley ${ }^{31,32}$ descreveram a preparação de nanopartículas $\mathrm{Pt}: \mathrm{Ru}$ suportadas em carbono, preparadas a partir do cluster $\mathrm{PtRu}_{5} \mathrm{C}(\mathrm{CO})_{16}$. Os resultados mostraram que a ativação do cluster precursor em atmosfera de hidrogênio a $400{ }^{\circ} \mathrm{C}$ levou à formação de partículas bimetálicas, com distribuição de partículas excepcionalmente estreita de cerca de 1,5 nm. A distribuição da composição apresentouse centrada na relação atômica Pt:Ru de 1:5, indicando uma coalescência uniforme do cluster precursor durante a ativação. Posteriormente, foi também utilizado como precursor o cluster $\mathrm{Pt}_{2} \mathrm{Ru}_{4}(\mathrm{CO})_{18}$ e, também neste caso, as nanopartículas obtidas apresentavam uma composição atômica Pt:Ru de 2:4 e diâmetros médios entre 1,0 e $1,5 \mathrm{~nm}$. Nos dois casos, os estudos por EXAFS revelaram uma distribuição não uniforme dos átomos metálicos nas nanopartículas. Os átomos de platina apresentavam uma preferência acentuada pela segregação para a superfície da partícula, quando o eletrocatalisador era tratado termicamente sob atmosfera de hidrogênio. Apesar do objetivo inicial destes estudos ser a aplicação dos materiais como eletrocatalisadores em células a combustível, não existem relatos na literatura a este respeito. Além disso, estes materiais apresentam composições ricas em rutênio para aplicações em células a combustível alimentadas com misturas hidrogênio/CO ou metanol diretamente como combustível. É conhecido que razões atômicas Pt:Ru de 1:1 apresentam melhor performance nestes casos. Baseados nestes resultados Lukehart e colaboradores ${ }^{33-35}$ utilizaram como precursor o complexo $(\eta-$ $\left.\mathrm{C}_{2} \mathrm{H}_{4}\right)(\mathrm{Cl}) \mathrm{Pt}(\mu \mathrm{Cl})_{2} \mathrm{Ru}(\mathrm{Cl})\left(\eta^{3}: \eta^{3}-\mathrm{C}_{10} \mathrm{H}_{16}\right)$. Este precursor foi incorporado em diversos suportes de carbono e tratado em condições oxidantes e redutoras apropriadas. As análises das partículas formadas revelaram que apresentavam uma estequiometria $\mathrm{Pt}: \mathrm{Ru}$ bem próxima de 1:1. Os materiais foram testados como ânodo em células a combustível usando metanol diretamente como combustível e, em alguns casos, mostraram-se mais ativos que os eletrocatalisadores comerciais E-TEK

Dickinson e colaboradores ${ }^{36}$ descreveram a preparação de eletrocatalisadores Pt:Ru a partir de uma mistura de clusters carbonilados. Neste caso, os clusters carbonilados $\left[\mathrm{Pt}_{3}(\mathrm{CO})_{3}\left(\mu_{2}-\mathrm{CO}\right)_{3}\right]_{\mathrm{x}}{ }^{2-} \mathrm{e}$ $\mathrm{Ru}_{3}(\mathrm{CO})_{12}$, na razão atômica Pt:Ru de $1: 1$, e o suporte de carbono 
foram colocados em $o$-xileno e refluxados a $143^{\circ} \mathrm{C}$ por $24 \mathrm{~h}$. O catalisador obtido apresentou nanopartículas $\mathrm{Pt}: \mathrm{Ru}$ pequenas $(2,5 \mathrm{~nm})$, homogeneamente distribuídas no suporte e com uma distribuição de tamanho bem estreita $(0,5 \mathrm{~nm})$. No entanto, a deposição de rutênio foi mais efetiva que a de platina nas condições utilizadas obtendo-se valores de 62-67 átomo\% para o rutênio e 33-38 átomo\% para a platina nas diferentes medidas feitas por EDX na amostra. A performance normalizada deste eletrocatalisador na oxidação direta de metanol, quando comparada ao eletrocatalisador comercial da E-TEK (Pt:Ru 50:50 átomo\%), mostrou que a baixos valores de corrente o catalisador da E-TEK apresenta melhor performance, provavelmente, devido à razão atômica de 33:67 átomo\% não ser a mais adequada para oxidação de metanol. No entanto, para valores acima de $145 \mathrm{~A} \mathrm{~g}^{-1}$ de metal a tendência é inversa, provavelmente devido à maior área superficial eletroquimicamente ativa $\left(27,7 \mathrm{~m}^{2} \mathrm{~g}^{-1}\right)$ que a do catalisador comercial $\left(22,2 \mathrm{~m}^{2} \mathrm{~g}^{-1}\right)$.

\section{MÉTODO DA REDUÇÃo POR ÁLCOOL}

O método da redução por álcool foi desenvolvido por Toshima e Yonezawa $^{37}$, para preparar dispersões coloidais de nanopartículas apresentando tamanho e distribuição bem uniformes. Neste método, o refluxo de uma solução alcoólica contendo o íon metálico na presença de um agente estabilizante, normalmente um polímero, fornece dispersões coloidais homogêneas das nanopartículas metálicas correspondentes. O álcool funciona como solvente e agente redutor, sendo oxidado a aldeídos e cetonas (Equação 9).

$\mathrm{H}_{2} \mathrm{PtCl}_{6}+2 \mathrm{CH}_{3} \mathrm{OH} \leftrightarrow \mathrm{Pt}^{0}+2 \mathrm{HCHO}+6 \mathrm{HCl}$

Este método apresenta as seguintes vantagens: i) o procedimento é muito simples e reprodutível, ii) as nanopartículas obtidas são pequenas e apresentam-se bem distribuídas, iii) o tamanho das nanopartículas pode ser controlado alterando as condições de preparação, como escolha do álcool, temperatura de redução, quantidade e variedade do agente estabilizante, concentração do íon metálico e uso de aditivos, iv) as dipersões coloidais das nanopartículas apresentam alta atividade catalítica e v) as dispersões obtidas são bastante estáveis.

Wang e Hsing ${ }^{38}$ prepararam eletrocatalisadores Pt/C e Pt:Ru/C através do método da redução por álcool. Para isto, uma solução metanol-água contendo os sais de platina e de rutênio foi refluxada na presença de um agente estabilizante (surfactante SB12) e do suporte de carbono. As análises por DRX, TEM e XPS mostraram que as nanopartículas (tamanho médio de 2,5 nm) apresentavam-se bem dispersas e suportadas no carbono. A caracterização eletroquímica mostrou que, em comparação ao eletrocatalisador comercial da ETEK, o eletrocatalisador Pt/C apresentou atividade catalítica similar para a reação de redução de oxigênio, enquanto que o eletrocatalisador PtRu/C apresentou maior tolerância ao envenenamento pelo monóxido de carbono.

Recentemente, Lee e colaboradore ${ }^{39}$ preparam o eletrocatalisador $\mathrm{Pt} / \mathrm{C}$ pelo método da redução por álcool. Uma solução aquosa de $\mathrm{H}_{2} \mathrm{PtCl}_{6} \cdot 6 \mathrm{H}_{2} \mathrm{O}$ foi adicionada ao álcool e uma pequena quantidade de solução aquosa de $\mathrm{KOH}$ foi adicionada gota a gota. Uma razão molar $\mathrm{KOH} / \mathrm{Pt}=8$ foi usada para induzir a formação de nanopartículas pequenas e bem uniformes. O suporte de carbono foi disperso nesta solução usando ultra-som e a mistura resultante foi aquecida em forno de microondas por $60 \mathrm{~s}$. A suspensão resultante foi filtrada, lavada com acetona e seca. As medidas por EDX indicaram a incorporação de 9,$5 ; 13,6$ e 18,6\% em massa para as amostras preparadas a partir de 10, 15 e $20 \%$ em massa de platina. As análises por TEM mostraram que as nanopartículas de platina obtidas apresentavam-se bem uniformes e distribuídas na superfície do carbono. O material contendo $18,6 \%$ em massa de platina apresentou nanopartículas na faixa de 3,5 a $4,0 \mathrm{~nm}$ e poucas partículas maiores que $5,0 \mathrm{~nm}$. O eletrocatalisador comercial Pt/C E-TEK (20\% em massa de Pt), usado para comparação, apresentou tamanho médio de nanopartículas de 5,1 nm e uma ampla distribuição entre 2 e $10 \mathrm{~nm}$. As medidas eletroquímicas mostraram que o eletrocatalisador $\mathrm{Pt} / \mathrm{C}$ preparado desta forma apresentou maior atividade na eletro-oxidação de metanol à temperatura ambiente que o catalisador comercial da E-TEK.

\section{CONSIDERAÇÕES FINAIS}

Os diversos métodos apresentados mostram diferentes abordagens na preparação de eletrocatalisadores, que oferecem maior ou menor grau de controle da distribuição, composição e do tamanho das nanopartículas produzidas. Alguns métodos permitem a preparação de sistemas de nanopartículas metálicas sendo, portanto, vantajosos para o estudo isolado dessas partículas e da interação com o suporte. Já outros métodos envolvem a preparação direta do eletrocatalisador suportado. É fundamental destacar que as características do eletrocatalisador obtido dependem não somente do método utilizado, mas também das condições de preparação. Assim, o objetivo deve ser sempre a produção de nanopartículas de tamanho adequado $(2-5 \mathrm{~nm})$, monodispersas e que apresentem uma distribuição homogênea no suporte. Estas características têm demonstrado serem as mais adequadas para se obter o máximo desempenho de um eletrocatalisador.

\section{AGRADECIMENTOS}

Agradecemos à FAPESP e ao CNPq pelos auxílios financeiros concedidos.

\section{REFERÊNCIAS}

1. Kordesch, K.; Berlin Bun. Fur Phy. Chem. 1990, 94, 902.

2. Du Melle, F.; J. Power Sources 1998, 71, 7.

3. Ticianelli, E. A.; Gonzalez, E. R.; Quim. Nova 1989, 12, 268.

4. Linardi, M.; Quim. Nova 2000, 25, 470.

5. Wendt, H.; Götz, M.; Linardi, M.; Quim. Nova 2000, 23, 538.

6. Gonzalez, E. R.; Quim. Nova 2000, 23, 262.

7. Lamy, C.; Lima, A.; LeRhun, V.; Delime, F.; Coutanceau, C.; Léger, J-M.; J. Power Sources 2002, 105, 283.

8. Iwasita, T.; Electrochim. Acta 2002, 47, 3663.

9. Gates, B. C.; Catalytic Chemistry, John Wiley \& Sons, Inc.: New York, 1992, cap. 6, p. 378.

10. Castro Luna, A. M.; Câmara, G. A.; Paganin, V. A.; Ticianelli, E. A.; Gonzalez, E. R.; Electrochem. Commun. 2000, 2, 222.

11. Oliveira Neto, A.; Tese de Doutorado, Universidade de São Paulo, Brasil, 2001.

12. Gasteiger, H. A.; Markovic, N. M.; Ross, P. N.; Cairns, E. J.; J. Electrochem Soc. 1994, 141, 1795.

13. Fujiwara, N.; Friedrich, K. A.; Stimming, U.; J. Electroanal. Chem. 1999, 472,120 .

14. Bönnemann, H.; Brijoux, W.; Brinkmann, R.; Dinjus, E.; Jouben, T.; Korall, B.; Angew. Chem., Int. Ed. 1991, 30, 1312.

15. Götz, M.; Wendt, H.; Eletrochim. Acta 1998, 43, 3637.

16. Radmilovic, V.; Gasteiger, H. A.; Ross Jr., P. N.; J. Catal. 1995, 154, 98.

17. Faubert, G.; Guay D.; Dodelet, J. P.; J. Eletrochem. Soc. 1998, 145, 2985.

18. Schmidt, T. J.; Gasteiger, H. A.; Behm, R. J.; Eletrochem. Commun. 1999, 1,1 .

19. Franco, E. G.; Oliveira Neto, A.; Linardi, M.; Arico, E.; J. Braz. Chem. Soc. 2002, 13, 516.

20. Oliveira Neto, A.; Franco, E. G.; Linardi, M.; Arico, E.; J. Eur. Ceram. Soc., no prelo.

21. Neto, A. O.; Giz, M. J.; Perez, J.; Ticianelli, E. A.; Gonzalez, E. R.; J. Electrochem. Soc. 2002, 149, A272.

22. Oliveira Neto, A.; Franco, E. G.; Linardi, M.; Arico, E.; Resumos da 25aㅡ Reunião Anual da Sociedade Brasileira de Química, Poços de Caldas, Brasil, 2002. 
23. Oliveira Neto, A.; Franco, E. G.; Linardi, M.; Arico, E.; XV Congresso da Sociedade Ibero-Americana de Electroquímica - SIBAE, Évora, Portugal, 2002.

24. Oliveira Neto, A.; Franco, E. G.; Arico, E.; Spinacé, E. V.; Linardi, M.; Fuel Cells Science and Technology 2002 Scientific Advances in Fuel Cells Systems, Amsterdam: Holanda, 2002.

25. Brankovic, S. R.; McBreen, J.; Adzic, R. R.; J. Electroanal. Chem. 2001, 503, 99.

26. Brankovic, S. R.; Wang, J. X.; Adzic, R. R.; Electrochem. Solid-State Lett. 2001, 4, A217.

27. Brankovic, S. R.; Wang, J. X.; Adzic, R. R.; J. Serb. Chem. Soc. 2001, 66, 887.

28. Waszczuk, P.; Solla-Gullon, J.; Kim, H. S.; Tong, Y. Y.; Montie, V.; Aldaz, A.; Wieckowski, A.; J. Catal. 2001, 203, 1.

29. Chrzanowski, W.; Wieckowski, A.; Langmuir 1997, 13, 5974

30. Oliveira Neto, A.; Franco, E. G.; Spinacé, E. V.; Linardi, M.; Anais do XIII Simpósio Brasileiro de Eletroquímica e Eletroanalítica, Araraquara, Brasil, 2002.
31. Nashner, M. S.; Frenkel, A. I.; Adler, D. L.; Shapley, J. R.; Nuzzo, R.G.; J. Am. Chem. Soc. 1997, 119, 7760.

32. Hills, C. W.; Nashner, M. S.; Frenkel, A. I.; Shapley, J. R.; Nuzzo, R. G.; Langmuir, 1999, 15, 690 .

33. Boxall, D. L.; Deluga, G. A.; Kenik, E.A.; King, W. D.; Lukehart, C. M.; Chem. Mater. 2001, 13, 891 .

34. Steigerwalt, E. S.; Deluga, G. A.; Cliffel, D. E.; Lukehart, C. M.; J. Phys. Chem. B 2001, 105, 8097.

35. Steigerwalt, E. S.; Deluga, G. A.; Lukehart, C. M.; J. Phys. Chem. B 2002, 106, 760 .

36. Dickinson, A. J.; Carrette, L. P. L.; Collins, J. A.; Friedrich, K. A.; Stimming, U.; Electrochim. Acta 2002, 47, 3733.

37. Toshima, N.; Yonezawa, T.; New J. Chem. 1998, 1179.

38. Wang, X.; Hsing, I-M.; Electrochim. Acta 2002, 47, 2981.

39. Chen, W. X.; Lee, J. Y.; Lui, Z.; Chem. Commun. 2002, 2588. 